\title{
FREE WILL BELIEF AS A PREDICTOR OF SELF-HANDICAPPING
}

\author{
William M. Jettinghoff
}

Submitted to the faculty of the Department of Psychological and Brain Sciences in partial fulfillment of the requirements for the Honors degree in Psychology

Indiana University

April $18^{\text {th }}, 2018$ 
Accepted by the Psychological and Brain Sciences Faculty, Indiana University, in partial fulfillment of the requirements for the Honors degree in Psychology.

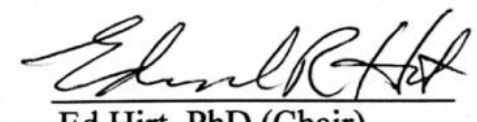

Ed Hirt, $\mathrm{PhD}$ (Chair)

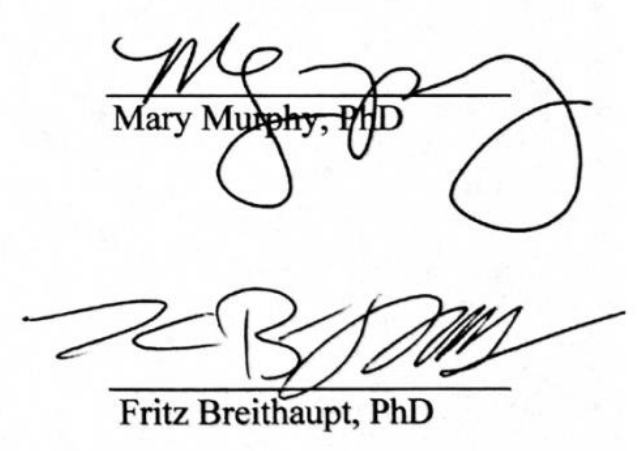

April, 2018 


\section{Acknowledgements}

I wish to sincerely thank those who sat on my thesis committee for their patience, challenging questions, and helpful feedback. I would especially like to thank my advisor, Dr. Ed Hirt, and his graduate student, Julie Eyink, who served as my mentor. They have both offered tremendous support and advice throughout my

three years in the lab. Because of their guidance, I have developed as a researcher and been able to accomplish so much. 


\title{
William M. Jettinghoff
}

Free Will Belief as a Predictor of Self-Handicapping

\begin{abstract}
The present research explores free will belief as a causal antecedent to selfhandicapping. The overarching goal of this work is to increase our understanding of why some individuals faced with a threatening assessment in an important ability domain will increase effort to ensure success, whereas others will engage in selfhandicapping. Previous work has established that uncertainty aroused by noncontingent success feedback encourages the use of self-handicapping. We theorize that when faced with uncertainty and potential failure, those with weaker free will beliefs will be more likely to resort to self-handicapping. In other words, that selfhandicapping necessitates that an individual feels a lack of free will and control over future performance and outcomes. Thus, we predicted that stronger belief in free will would be negatively associated with self-handicapping. Study $1(\mathrm{~N}=137)$ used a correlational design and measured trait self-handicapping, belief in free will, and perceptions of control, among other relevant dispositional variables, in an MTurk sample. The results indicated that belief in free will was negatively correlated with trait self-handicapping. Study $2(\mathrm{~N}=132)$ replicated this same pattern using a correlational design with a college student sample. Study $3\left(\mathrm{~N}=98^{*}\right)$ used an experimental design and manipulated belief in free will using an autobiographical memory task in which participants were asked to recall a time in which they experienced control and freedom of choice, or a lack thereof. We predicted that experimentally inducing a weaker free will belief would increase claimed self-
\end{abstract}


handicapping. Results showed that the memory task did not produce differences in belief in free will, making us unable to test our causal hypothesis. However, we did replicate the correlations found in Studies 1 and 2. The free will manipulation and the implications of the correlational data are discussed. 


\section{Introduction}

Self-handicapping is a self-protective strategy used in the face of uncertainty about future performance, and the resultant threat of failure (Berglas \& Jones, 1978). To protect themselves from the implications of failure, self-handicappers construct obstacles to successful performance to manipulate self-attributions. By doing so, the handicapper is able to evade the implications of failure by externalizing it to the handicap, rather than their lack of ability in the domain being assessed. For example, prior to an important test (e.g, the GRE) an individual may withdraw effort by not studying for the exam, that way they can blame their failure on their lack of studying rather than their ability. Self-handicapping is, consequentially, a self-defeating strategy that has been associated with negative coping behaviors (Zuckerman, Kieffer, \& Knee, 1998), increased substance use (Zuckerman \& Tsai, 2005), and poorer academic achievement (Schwinger, Wirthwein, Lemmer, \& Steinmayr, 2014). Understanding the antecedents to selfhandicapping would enable researchers to unpack the decision-making processes that result in this harmful behavior, and thereby to arm educators with interventions that might prevent the use of self-handicapping.

However, it is still unclear why some individuals respond to uncertainty and the threat of failure with increased effort while others respond by self-handicapping. This research explores how belief in free will can help explain the use of self-handicapping by some, but not by others. We theorize that in response to uncertainty, handicappers perceive their choices as inconsequential to the outcome of their performance and perceive a lack of control over the outcome. The growing body of research outlining the beliefs that lay people hold about free will has shown that belief in free will is, 
essentially, belief in choice and control over behavior. Therefore, it follows that weaker belief in free will may, in part, explain why some people turn to self-handicapping in response to the threat of uncertainty and failure while others do not.

\section{Self-Handicapping and Uncertainty}

Berglas and Jones' (1978) seminal work tested the hypothesis that uncertainty leads to self-handicapping by examining conditions in which people could handicap by taking a performance debilitating drug prior to an important test. In their first experiment, participants were asked to complete two purportedly valid intelligence tests. The first test was comprised of either easy or unsolvable problems. Regardless of which test had been completed, participants were told that they had performed well. For those who completed the unsolvable problems, this feedback was given to arouse uncertainty about the means to success. This "non-contingent success feedback" would leave them unsure of how to replicate their performance and uphold a successful self-image. After the feedback, participants were given the choice between a performance enhancing or debilitating drug before taking the second IQ test. This drug choice served as an opportunity to selfhandicap. If one chose the performance debilitating drug, then they could blame their poor performance on the effects of the drug, rather than their own lack of ability.

Berglas and Jones hypothesized that participants would self-handicap more after being given success feedback on the unsolvable problems (i.e., non-contingent success feedback). They reasoned that non-contingent success feedback would arouse uncertainty about the means to successful performance, and therefore how to defend a positive selfimage. Their results supported this hypothesis - participants given success feedback on the unsolvable problems self- handicapped more than those who had completed the easy 
problems. In the authors' interpretation, uncertainty about how to replicate previous successful performance led participants to self-handicap in order to protect their selfimage. The effect of non-contingent success feedback on self-handicapping has since been replicated multiple times (Arkin \& Baumgartner, 1985; Mayerson \& Rhodewalt, 1988; Hirt, Deppe, \& Gordon, 1991).

\section{Self-Handicapping and Attribution Manipulation}

While evidence supports the notion that self-handicapping is a harmful strategy to use in the long-term (Zuckerman, et al., 1998; Zuckerman \& Tsai, 2005; Schwinger et al., 2014), it does have psychological benefits immediately following performance. Indeed, Rhodewalt, Morf, Hazlett, and Fairfield (1991) found that following failure feedback, those who self-handicapped reported higher self-esteem than those who did not handicap themselves prior to an assessment. Furthermore, McCrea and Hirt (2001) found that, following failure, handicappers successfully protected beliefs about their ability in a specific domain through the performance attributions afforded by self-handicapping. It was these beliefs about ability that mediated the positive effects of self-handicapping on self-worth. Therefore, from the handicapper's point-of-view, self- handicapping is a rather effective strategy for controlling their self-image. By placing a barrier between themselves and success, handicappers are able to successfully manipulate self-attributions, thereby preserving self-perceptions of ability and protecting self-worth. In other words, while uncertainty about the means to success triggers self-handicapping, it is the ability to manipulate attributions for failure that makes self-handicapping such a compelling strategy. Still, it is not clear why, given uncertainty, some choose to handicap and take advantage of the benefits of attribution manipulation it affords while others do not. 


\section{Uncertainty, Choice, and Control}

In sum, situations arousing uncertainty about the means to success elicit selfhandicapping especially strongly. This is evidenced in the consistent observation that self-handicapping is especially likely to occur in response to non-contingent success feedback (Berglas \& Jones, 1978; Arkin \& Baumgartner, 1985; Mayerson \& Rhodewalt, 1988; Hirt, Deppe, \& Gordon, 1991). Research conducted by Hirt, McCrea, and Kimble (2000) has shown that this relationship is mediated by feelings of concern for failure.

Specifically, these authors found that those who engaged in self-handicapping expressed greater uncertainty and concern about their future performance relative to those who did not engage in self-handicapping. Indeed, this research demonstrated that the effects of non-contingent success feedback on self-handicapping are mediated by feelings of uncertainty and concern about future performance (i.e., concern for failure).

This suggests that self-handicapping may be caused by feeling that one's choices will make little difference as to the outcome of the situation. In situations arousing uncertainty about the means to success, handicappers may believe that successful performance is contingent upon forces outside of one's control - such as luck, chance, contextual factors, or other people. Such self-perceived lack of choice and control may then motivate self-handicapping under the belief that one's choices will not have a positive impact on the upcoming performance, and that failure is likely.

\section{The Folk Concept of Free Will}

In an effort to establish a lay concept of free will, Monroe and Malle (2009) found that belief in free will is essentially belief in freedom of choice of action. Similarly, Stillman, Baumeister, and Mele (2011) found that people define free actions as those that 
involve conscious deliberation, progress towards a particular goal, and that are morally good. They conclude that, to lay people, having free will is having control over our actions. Together, such work has shown that most people think of having free will as having choice and control over their actions.

\section{Belief in Free Will and Locus of Control}

Stillman, Baumeister, Vohs, Lambert, Fincham, and Brewer (2010) set out to examine the effects of free will belief on job-related outcomes. They found that, in a student sample, free will belief was a stronger predictor of self-reported predicted job success than internal locus of control. Extending their inquiry to an adult sample, Stillman and her colleagues' (2010) second study measured actual job performance as rated by a supervisor. They found that belief in free will, by the employees, was positively correlated with overall job performance as well as a spectrum of specific performance criteria, including work effort, consistency, and positive social impact at work.

In another domain, Crescioni, Baumeister, Ainsworth, Ent, and Lambert (2015) explored the relationship between free will belief and life satisfaction. They found that free will belief was positively correlated with life satisfaction, self-efficacy, and perceived meaning in life. Again, like Stillman et al. (2010), they found free will belief to be a better predictor of these trait measures than internal locus of control. Taken together, the

literature on free will belief does evidence a strong relationship between belief in free will and internal locus of control. However, evidence suggests that free will belief is a distinct construct that independently predicts certain behavioral outcomes (Stillman et al., 2010) and trait measures (Crescioni et al., 2015). 


\section{Self-Handicapping and Belief in Free Will}

In sum, self-handicapping is motivated by uncertainty about future performance. This suggests that handicappers may feel that their choices will have little impact on the situation and that they do not feel that they have control over the outcome. Furthermore, people think of having free will as having freedom of choice and being in control of their actions (Monroe \& Malle, 2010; Stillman et al., 2011). Therefore, it follows that weakened belief in free will would drive someone to self-handicap. Perceiving one's choices as having little impact on the outcome and viewing themselves as not having control over their performance, one may choose to self-handicap to avoid the implications of failure that they cannot otherwise evade. That is, individuals lacking belief in free will may not believe that increased effort will result in greater success and may opt to engage in self-handicapping as a means of protecting their fragile self-esteem. Establishing such a relationship between belief in free will and self-handicapping will further illuminate the relationship between uncertainty and self-handicapping and provide an explanation for why some choose to self-handicap in the face of uncertainty while others put forth effort towards success.

To test the hypothesis that belief in free will is negatively associated with selfhandicapping, we conducted three studies. In the first study, a survey was administered to an adult sample of MTurk workers to examine the correlations between belief in free will, trait self-handicapping, and other relevant constructs. Study 2 used a similar correlational design and administered a survey to a sample of undergraduate students. Finally, Study 3 used an experimental design attempting to manipulate belief in free will and the viability of a handicap to test the causal impact of belief in free will on self-handicapping. 


\section{Study 1}

The purpose of Study 1 was to explicate the relationship between selfhandicapping (Jones \& Rhodewalt, 1982) and free will beliefs (Rakos, Laurene, Skala, \& Slane, 2008; Paulhus \& Carey, 2011; Deery, Davis, \& Carey, 2015), as well as related constructs such as beliefs about control (Levenson, 1973; Lefcourt, von Baeyer, Ware, \& Cox, 1979), and effort (Schwarzer Bäßler, Kwiatek, Schröder, \& Zhang, 1997; McCrea, Hirt, Hendrix, \& Milner, 2008). We expected that there would be a positive relationship between free will beliefs, internal locus of control, self-efficacy, and belief in the value of effort, as well as a negative relationship between these constructs and scores on the selfhandicapping scale.

\section{Method}

\section{Participants \& Design}

Participants were 181 adult native English-speaking Mechanical Turk (MTurk) workers from across the United States whom participated in exchange for \$1 as payment. This study used a correlational design in which participants completed a variety of questionnaires to establish expected relationships between free will beliefs, selfhandicapping, locus of control, and various other expected correlates including belief in the value of effort, self-efficacy, contingencies of self-worth, gender, and political ideology. Information about all scales used in Study 1 can be found in Appendix A.

\section{Procedure}

Participants signed up for the online study on MTurk after selecting it from a list of potential tasks called Human Interaction Tasks (HITs). The study was completed at a location and time of their choosing. After selecting the study, participants followed a link 
to a Qualtrics survey. Once they had consented to take part in the study, participants completed various scales regarding self-handicapping, free will beliefs, locus of control, and expected correlates of self-efficacy and contingencies of self-worth. All scales were presented in a random order, and the order of questions within each scale were randomized. There were also two attention check questions randomly displayed in the survey. After completing all of the scales, participants completed a demographic questionnaire. Upon finishing all questions, participants were debriefed, thanked for their participation, and given a unique payment code to use on the MTurk site for reimbursement.

\section{Study 1 Results}

\section{Descriptive Statistics}

This study used correlational analyses to establish the expected relationships between the various scales used in the survey. Participants were 181 Amazon Mechanical Turk workers; however, after filtering out participants who had failed either one of the two attention checks, data were only analyzed for 137 participants. Mean age was 35.45 years, and 74 participants identified as women and 63 as men. Of the 137 participants whose data were used, $74.5 \%$ identified as White Caucasian, $9.5 \%$ as Black, $7.3 \%$ as Asian, $6.6 \%$ as Hispanic/Latino, $1.5 \%$ as Middle Eastern, and 0.7\% identified as mixed race.

\section{Correlations}

Free Will, Control, and Self-Handicapping. Two measures of free will belief were significantly negatively correlated with the self-handicapping scale (SHS), such that a stronger belief in free will was associated with a weaker disposition to self-handicap. 
Specifically, the personal will subscale of the free will and determinism scale (FWDS; $r=$ $-.304, \mathrm{p}<.01)$ and the free will subscale of the Free Will and Determinism-Plus scale (FAD-Plus; $\mathrm{r}=-.226, \mathrm{p}<.01$ ) were significantly negatively correlated with SHS scores.

Similarly, the SHS was significantly negatively correlated with the internal subscale of the Multidimensional Locus of Control (MLOC) scale ( $r=-.403, p<.01)$, such that having a stronger belief in an internal locus of control was associated with lower trait self-handicapping. Furthermore, the SHS was significantly positively correlated with the chance $(r=.600, \mathrm{p}<.01)$ and powerful others $(\mathrm{r}=.534, \mathrm{p}<.01)$ subscales of the MLOC, indicating that higher trait self-handicapping is positively related with having either type of external locus of control.

Free Will Belief and Control. Free will beliefs significantly positively correlated with internal locus of control as measured by the internal subscale of the MLOC, indicating that the stronger someone's belief in free will, the stronger their belief in an internal locus of control. Specifically, the positive correlations between the internal subscale of the MLOC and the free will subscale of the FAD-Plus $(r=.515, \mathrm{p}<.01)$ and personal will subscale of the FWDS $(\mathrm{r}=.519, \mathrm{p}<.01)$ were highly significant.

Two measures of free will belief were also found to be significantly negatively correlated with all measures of external locus of control. The FWDS was significantly negatively correlated with the chance $(r=-.505, \mathrm{p}<.01)$ and powerful others $(r=-.430$, $\mathrm{p}<.01)$ subscales of the MLOC, such that a stronger belief in personal free will is associated with a less external locus of control. Following this same pattern, the free will subscale of the FAD-Plus also achieved significant negative correlations with the chance $(\mathrm{r}=-.267, \mathrm{p}<.01)$ and powerful others $(\mathrm{r}=-.219, \mathrm{p}<.01)$ subscales of the MLOC, such that 
a stronger belief in free will was associated with a less external locus of control.

Free Will, Effort, and Self-Efficacy. Free will beliefs were significantly positively correlated with measures regarding effort and self-efficacy. The free will subscale of the FAD-Plus was significantly positively correlated with the Worker Scale $(r=.357, p<.05)$, such that stronger belief in free will indicate a stronger belief in the value of effort. Two measures of free will belief were significantly positively correlated with general selfefficacy (GSE), such that higher belief in free will was related to a stronger belief in selfefficacy. The free will subscale of the FAD-Plus $(r=.359, \mathrm{p}<.01)$ and the personal will subscale of the FWDS $(\mathrm{r}=.383, \mathrm{p}<.01)$ were significantly positively correlated with GSE.

Self-Efficacy, Value of Effort, and Self-Handicapping. GSE was significantly negatively correlated with the SHS $(r=-.374, \mathrm{p}<.01)$, such that higher self-efficacy was associated with lower trait self-handicapping. The Worker Scale, indexing belief in the value of effort, was also significantly negatively correlated with the SHS ( $r=-.465$, $\mathrm{p}<.01$ ), such that stronger belief in the value of effort was associated with lower trait selfhandicapping. Lastly, GSE was significantly positively correlated with the Worker scale $(\mathrm{r}=.359, \mathrm{p}<.01)$, such that stronger belief in self-efficacy was related to stronger belief in the value of effort. Correlations for Study 1 can be found in Table 1.

\section{Study 1 Discussion}

We hypothesized that trait self-handicapping would be significantly negatively correlated with belief in free will and internal locus of control. We also hypothesized that free will belief would be positively correlated with internal locus of control, and negatively correlated with external loci of control. Furthermore, influenced by past work demonstrating a relationship between self-handicapping and beliefs about effort, it was 


\begin{tabular}{|c|c|c|c|c|c|c|c|c|}
\hline$N=137$ & $\begin{array}{l}\text { Self- } \\
\text { Handicapping } \\
\text { Scale }\end{array}$ & $\begin{array}{l}\text { Free Will } \\
\text { Subscale of } \\
\text { FAD-Plus }\end{array}$ & $\begin{array}{l}\text { Personal Will } \\
\text { Subscale of } \\
\text { FWDS }\end{array}$ & $\begin{array}{l}\text { Internal Locus } \\
\text { of Control }\end{array}$ & $\begin{array}{l}\text { Powerful } \\
\text { Others Locus } \\
\text { of Control }\end{array}$ & $\begin{array}{l}\text { Chance Locus } \\
\text { of Control }\end{array}$ & Worker Scale & $\begin{array}{l}\text { General Self- } \\
\text { Efficacy }\end{array}$ \\
\hline $\begin{array}{l}\text { Self- } \\
\text { Handicapping } \\
\text { Scale }\end{array}$ & 1 & & & & & & & \\
\hline $\begin{array}{l}\text { Free Will } \\
\text { Subscale of } \\
\text { FAD-Plus }\end{array}$ & $\begin{array}{l}-.226 \\
p<.01\end{array}$ & 1 & & & & & & \\
\hline $\begin{array}{l}\text { Personal Will } \\
\text { Subscale of } \\
\text { FWDS }\end{array}$ & $\begin{array}{l}-.304 \\
p<.001\end{array}$ & $\begin{array}{l}.469 \\
p<.001\end{array}$ & 1 & & & & & \\
\hline $\begin{array}{l}\text { Internal Locus } \\
\text { of Control }\end{array}$ & $\begin{array}{l}-.403 \\
p<.001\end{array}$ & $\begin{array}{l}.515 \\
p<.001\end{array}$ & $\begin{array}{l}.519 \\
p<.001\end{array}$ & 1 & & & & \\
\hline $\begin{array}{l}\text { Powerful } \\
\text { Others Locus } \\
\text { of Control }\end{array}$ & $\begin{array}{l}.534 \\
p<.001\end{array}$ & $\begin{array}{l}-.219 \\
p<.05\end{array}$ & $\begin{array}{l}-.430 \\
p<.001\end{array}$ & $\begin{array}{l}-.428 \\
p<.001\end{array}$ & 1 & & & \\
\hline $\begin{array}{l}\text { Chance Locus } \\
\text { of Control }\end{array}$ & $\begin{array}{l}.600 \\
p<.001\end{array}$ & $\begin{array}{l}-.267 \\
p<.01\end{array}$ & $\begin{array}{l}-.505 \\
p<.001\end{array}$ & $\begin{array}{l}-.612 \\
p<.001\end{array}$ & $\begin{array}{l}.680 \\
p<.001\end{array}$ & 1 & & \\
\hline Worker Scale & $\begin{array}{l}-.465 \\
p<.001\end{array}$ & $\begin{array}{l}.357 \\
p<.001\end{array}$ & $\begin{array}{l}.160 \\
p=.062\end{array}$ & $\begin{array}{l}.435 \\
p<.001\end{array}$ & $\begin{array}{l}-.100 \\
p=.241\end{array}$ & $\begin{array}{l}-.338 \\
p<.001\end{array}$ & 1 & \\
\hline $\begin{array}{l}\text { General Self- } \\
\text { Efficacy }\end{array}$ & $\begin{array}{l}-.374 \\
p<.001\end{array}$ & $\begin{array}{l}.359 \\
p<.001\end{array}$ & $\begin{array}{l}.383 \\
p<.001\end{array}$ & $\begin{array}{l}.504 \\
p<.001\end{array}$ & $\begin{array}{l}-.197 \\
p<.05\end{array}$ & $\begin{array}{l}-.255 \\
p<.01\end{array}$ & $\begin{array}{l}.359 \\
p<.001\end{array}$ & 1 \\
\hline
\end{tabular}

Table 1 . Study 1 correlations. 
hypothesized that free will belief would be positively correlated with measures pertaining to the value and effectiveness of effort. Thus, it was predicted that free will belief would be significantly positively correlated with the Worker scale and general self-efficacy.

Analyses supported all of these hypotheses, and our results provide compelling evidence that the propensity to self-handicap is indeed negatively related with espousing a strong belief in free will and an internal locus of control. Furthermore, the disposition to self-handicap appears to be associated with holding a more external locus of control, or the belief that the events in our lives are caused by external forces such as chance and powerful others. Free will belief also appears to be positively related with beliefs about effort - participants with a stronger belief in free will reported valuing effort more and believing themselves to be more efficacious.

\section{Study 2}

The purpose of this study was to replicate the relationships found in Study 1 with a student sample, as that is the population on which subsequent experimental work would be conducted. We measured free will beliefs (Rakos et al., 2008; Paulhus \& Carey, 2011), self-handicapping (Jones \& Rhodewalt, 1982), locus of control (Levenson, 1973), and other expected correlates including belief in the value of effort (McCrea et al., 2008), self-efficacy (Schwarzer et al., 1997), contingencies of self-worth (Crocker et al., 2003), gender, and political ideology using the same scales as Study 1 . Three new scales were added, measuring lay theories of personality, beliefs about moral responsibility (Deery et al., 2015), and self-esteem (Rosenburg, 1965). We also added all of the subscales for the FAD-Plus and FWDS to capture more information about participants' beliefs in free will. Information about new scales used in Study 2 can be found in Appendix B. 
Contingencies of self-worth and the free will subscales of the Free Will Intuitions Scale (FWIS) were removed.

We predicted that self-handicapping would be negatively correlated with internal locus of control, self-efficacy, the Worker scale, and all measures of free will belief. Furthermore, it was predicted that self-handicapping would be positively correlated with all external loci of control as measured by the MLOC.

\section{Method}

\section{Participants \& Design}

Participants were 207 undergraduate students from a large public university in Indiana who participated for introductory psychology course research credit. This study used a correlational design in which participants completed a variety of questionnaires to establish expected relationships between free will beliefs, self-handicapping, locus of control, and various other expected correlates including effort beliefs, self-efficacy, moral responsibility, self-esteem, gender, and political ideology.

\section{Procedure}

Participants signed up for the online study on SONA, an online study management software. The study was selected from a list of potential studies that they could complete for course credit. Participants completed the survey from a location and time of their choosing. Once they had selected the study, participants followed a link to a Qualtrics survey. After consenting to take part in the study, participants completed various scales measuring beliefs about free will, determinism, self-handicapping, locus of control, effort beliefs, self-efficacy, responsibility, self-esteem, and political ideology. All scales were presented in a random order, where questions within each scale were 
randomized. The two attention checks used in Study 1 were also randomly displayed in the survey. After completing all of the scales, participants completed the same demographic questionnaire as in Study 1. Upon finishing all questions, participants were debriefed, thanked for their participation, and assigned course credit.

\section{Study 2 Results}

\section{Descriptive Statistics}

This study used correlational analyses to establish the expected relationships between the various scales used in the survey. Participants were 207 students from a large Midwestern university; however, after filtering out participants who had failed either of the two attention checks, data were analyzed for 132 participants. Mean age was 18.73 years, and 93 participants identified as women and 39 as men. Of the 132 participants whose data were used, $79.5 \%$ identified as White Caucasian, 2.3\% as Black, $7.6 \%$ as Asian, $2.3 \%$ as Hispanic/Latino, $0.8 \%$ as Middle Eastern, and 5.3\% identified as mixed race.

Correlations

Free Will, Control, Effort, and Self-Handicapping. The SHS was significantly negatively correlated with the personal will $(\mathrm{r}=-.251, \mathrm{p}<.01)$ and general will $(\mathrm{r}=-.280$, $\mathrm{p}<.01)$ subscales of the FWDS as well as the free will subscale $(r=-.297, \mathrm{p}<.01)$ of the FAD-Plus, such that a stronger belief in free will was related to lower dispositional levels of self-handicapping. The SHS was also significantly negatively correlated with internal locus of control $(\mathrm{r}=-.291, \mathrm{p}<.01)$, the Worker scale $(\mathrm{r}=-.578, \mathrm{p}<.001)$, and with GSE $(\mathrm{r}=-$ $.354, \mathrm{p}<.001)$. The SHS was significantly positively correlated with the chance $(\mathrm{r}=.343$, $\mathrm{p}<.001)$ and powerful others $(\mathrm{r}=.414, \mathrm{p}<.001)$ subscales of the MLOC. 
Free Will Belief, Locus of Control, and Beliefs about Effort. All measures of free will were significantly positively correlated with an internal locus of control as measured by the internal subscale of the MLOC, indicating that the stronger someone's belief in free will, the stronger their belief in an internal locus of control. Specifically, the internal subscale of the MLOC scale and the free will subscale of the FAD-Plus ( $r=.463, p<.001)$, personal will subscale of the FWDS $(r=.394, \mathrm{p}<.001)$, and the general will subscale of the FWDS ( $r=.368, p<.001)$ were all significantly positively correlated. The FWDS personal will subscale was significantly negatively correlated with the chance subscale of the MLOC $(r=-.230, p<.01)$, such that a stronger belief in personal free will was associated with a weaker belief that events are due to chance forces.

The Worker scale, indexing belief in the value of effort, was positively correlated with the personal will $(\mathrm{r}=.213, \mathrm{p}<.05)$ and general will $(\mathrm{r}=.249, \mathrm{p}<.01)$ subscales of the FWDS and the free will subscale of the FAD-Plus ( $r=.172$, $p<.05)$, such that a stronger belief in the value of effort is associated with a stronger belief in free will. The Worker scale was not significantly correlated with the internal subscale of the MLOC. However, it was significantly negatively correlated with both the powerful others $(\mathrm{r}=-.259, \mathrm{p}<.01)$ and chance $(\mathrm{r}=-.259, \mathrm{p}<.05)$ subscales of the MLOC, such that those who value effort more tend to believe that the external forces of powerful others and chance have less of an influence on life outcomes or events.

GSE was positively correlated with the personal will $(\mathrm{r}=.467, \mathrm{p}<.001)$ and general will $(\mathrm{r}=.332, \mathrm{p}<.001)$ subscales of the FWDS and the free will subscale of the FAD-Plus $(\mathrm{r}=.274, \mathrm{p}<.001)$, such that a stronger belief in self-efficacy is associated with a stronger belief in free will. GSE was also significantly positively correlated with the internal 
subscale of the MLOC $(r=.456, p<.001)$, such that a stronger belief in self-efficacy was related to a more internal locus of control. Lastly, GSE was significantly negatively correlated with both the powerful others $(r=-.272, p<.01)$ and chance $(r=-.260, p<.01)$ subscales of the MLOC. Correlations for Study 2 can be found in Table 2.

\section{Study 2 Discussion}

This research aimed to replicate the relationships found in Study 1 with a student sample. The purpose of this was to increase external validity, and to study the population upon which future experimental research would be conducted. We hypothesized that trait self-handicapping would be negatively correlated with belief in free will as well as internal locus of control, belief in the value of effort, and self-efficacy, and positively correlated with belief in chance forces and powerful others as exerting control over one's life. It was also predicted that free will belief would be positively correlated with an internal locus of control, and negatively correlated with external loci of control (i.e., chance and powerful others). Lastly, it was hypothesized that free will belief would be positively correlated with measures pertaining to the value and effectiveness of effort. Thus, we predicted that free will belief would be positively correlated with the Worker scale and general self-efficacy.

Self-handicapping was significantly negatively correlated with internal locus of control and free will belief. We believe this is because, feeling free, one feels in control of future behavior and performance, which disambiguates the means to success and undermines the uncertainty that leads to self-handicapping. Self-handicapping was positively correlated with belief in chance forces and powerful others as determinants of events in one's life. Given the causes and operation of self-handicapping, these results 


\begin{tabular}{|c|c|c|c|c|c|c|c|c|c|}
\hline$N=132$ & $\begin{array}{l}\text { Self- } \\
\text { Handicapping } \\
\text { Scale }\end{array}$ & $\begin{array}{l}\text { Free Will } \\
\text { Subscale of } \\
\text { FAD-Plus }\end{array}$ & $\begin{array}{l}\text { Personal Will } \\
\text { Subscale of } \\
\text { FWDS }\end{array}$ & $\begin{array}{l}\text { General Will } \\
\text { Subscale of } \\
\text { FWDS }\end{array}$ & $\begin{array}{l}\text { Internal Locus } \\
\text { of Control }\end{array}$ & $\begin{array}{l}\text { Powerful } \\
\text { Others Locus } \\
\text { of Control }\end{array}$ & $\begin{array}{l}\text { Chance Locus } \\
\text { of Control }\end{array}$ & Worker Scale & $\begin{array}{l}\text { General Self- } \\
\text { Efficacy }\end{array}$ \\
\hline $\begin{array}{r}\text { Self- } \\
\text { Handicapping } \\
\text { Scale }\end{array}$ & 1 & & & & & & & & \\
\hline $\begin{array}{l}\text { Free Will } \\
\text { Subscale of } \\
\text { FAD-Plus }\end{array}$ & $\begin{array}{l}-.297 \\
p=.001\end{array}$ & 1 & & & & & & & \\
\hline $\begin{array}{r}\text { Personal Will } \\
\text { Subscale of } \\
\text { FWDS }\end{array}$ & $\begin{array}{l}-.251 \\
p<.01\end{array}$ & $\begin{array}{l}.411 \\
p<.001\end{array}$ & 1 & & & & & & \\
\hline $\begin{array}{r}\text { General Will } \\
\text { Subscale of } \\
\text { FWDS }\end{array}$ & $\begin{array}{l}-.280 \\
p<.001\end{array}$ & $\begin{array}{l}.598 \\
p<.001\end{array}$ & $\begin{array}{l}.798 \\
p<.001\end{array}$ & 1 & & & & & \\
\hline $\begin{array}{r}\text { Internal Locus } \\
\text { of Control }\end{array}$ & $\begin{array}{l}-.291 \\
p<.001\end{array}$ & $\begin{array}{l}.436 \\
p<.001\end{array}$ & $\begin{array}{l}.394 \\
p<.001\end{array}$ & $\begin{array}{l}.368 \\
p<.001\end{array}$ & 1 & & & & \\
\hline $\begin{array}{r}\text { Powerful } \\
\text { Others Locus } \\
\text { of Control }\end{array}$ & $\begin{array}{l}.414 \\
p<.001\end{array}$ & $\begin{array}{l}-.076 \\
p=.389\end{array}$ & $\begin{array}{l}-.139 \\
p=.111\end{array}$ & $\begin{array}{l}-.055 \\
p=.528\end{array}$ & $\begin{array}{l}-.086 \\
p=.327\end{array}$ & 1 & & & \\
\hline $\begin{array}{r}\text { Chance Locus } \\
\text { of Control }\end{array}$ & $\begin{array}{l}.343 \\
p<.001\end{array}$ & $\begin{array}{l}-.145 \\
p=.097\end{array}$ & $\begin{array}{l}-.230 \\
p<.01\end{array}$ & $\begin{array}{l}-.141 \\
p=.108\end{array}$ & $\begin{array}{l}-.263 \\
p<.01\end{array}$ & $\begin{array}{l}.575 \\
p<.001\end{array}$ & 1 & & \\
\hline Worker Scale & $\begin{array}{l}-.578 \\
p<.001\end{array}$ & $\begin{array}{l}.172 \\
p<.05\end{array}$ & $\begin{array}{l}.213 \\
p<.05\end{array}$ & $\begin{array}{l}.249 \\
p<.01\end{array}$ & $\begin{array}{l}.127 \\
p=.147\end{array}$ & $\begin{array}{l}-.259 \\
p<.01\end{array}$ & $\begin{array}{l}-.259 \\
p<.01\end{array}$ & 1 & \\
\hline $\begin{array}{r}\text { General Self- } \\
\text { Efficacy }\end{array}$ & $\begin{array}{l}-.354 \\
p<.001\end{array}$ & $\begin{array}{l}.274 \\
p<.01\end{array}$ & $\begin{array}{l}.467 \\
p<.001\end{array}$ & $\begin{array}{l}.332 \\
p<.001\end{array}$ & $\begin{array}{l}.456 \\
\mathrm{p}<.001\end{array}$ & $\begin{array}{l}-.272 \\
p<.01\end{array}$ & $\begin{array}{l}-.260 \\
p<.001\end{array}$ & $\begin{array}{l}.319 \\
p<.001\end{array}$ & 1 \\
\hline
\end{tabular}

Table 2 . Study 2 correlations. 
make sense. Believing external forces to be important causal factors in one's life may make someone feel less control over performance outcomes, thereby increasing uncertainty and concern for failure.

Self-handicapping was also negatively correlated with belief in the value of effort (i.e., the Worker scale) as well as self-efficacy. The former finding not only replicates Study 1, but also past research establishing a link between self-handicapping and valuing effort (McCrea et al., 2008). Furthermore, the Worker scale was positively correlated with all measures of free will belief, but not with internal locus of control.

In short, the pattern of correlations found in Study 2 replicates the pattern of correlations found in Study 1. While not providing causal evidence for the hypothesis that weakened free will belief leads to more self-handicapping, the correlations obtained in Study 1 and Study 2 are consistent with the predictions made by this causal hypothesis. Study 3 sought to test this causal hypothesis directly.

\section{Study 3}

Studies 1 and 2 established a negative correlation between belief in free will and trait self-handicapping, such that stronger belief in free will was associated with lower trait self-handicapping. The purpose of Study 3 was to expand this correlational work by establishing a causal relationship between belief in free will and claimed selfhandicapping. We predicted, for high self-handicappers, a main effect of free will condition on claimed self-handicapping such that participants in the anti-free will condition should claim stress as a self-handicap significantly more than either those in the pro-free will or control condition who received no free will belief manipulation. We further predicted that the relationship between belief in free will and claimed self- 
handicapping would be mediated by concern for failure (i.e., uncertainty).

\section{Method}

\section{Participants \& Design}

Participants were 125 undergraduate students from a large public university in Indiana who participated for introductory psychology course research credit. This study used a 3 (Free Will Beliefs: High, Low, Control) x 2 (Stress Instructions: Stress Matters, Stress Doesn't Matter) x 2 (Trait Self-handicapping: High, Low) X 2 (Trait SelfHandicapping: High, Low) between-subjects factorial design. We manipulated belief in free will to be either high or low (or participants received no manipulation in a control condition). We also manipulated the validity of stress as a claimed handicap to be either valid or invalid (Hirt, Deppe, \& Gordon, 1991; Hirt, McCrea, \& Kimble, 2000; Kimble \& Hirt, 2005; McCrea, Hirt, \& Milner, 2008). Lastly, participants were designated as a high or low self-handicapper for analyses by conducting a median split on scores on the SHS.

\section{Procedure}

Participants signed up for the study on SONA after selecting it from a list of potential studies that they could complete for course credit and selected a time slot of their choosing to come into the lab. After arriving to the lab, participants sat in an individual testing room and were asked to read and sign a consent form. After providing informed consent, the experimenters told participants that they would be participating in two unrelated tasks. The experimenters told participants to open their testing room door when they had completed the first task to signal to the experimenter that they were ready to move on to the second task, and a message also appeared at the end of the survey instructing them to open the door. Participants completed the first task on Qualtrics. After 
completing the first task, an experimenter who was waiting in a nearby room exited the browser and set-up the second task on MediaLab, an experimental software. The use of two separate programs was meant to bolster the cover story that the tasks were unrelated.

In the first task, the experimenter told participants that they would be completing an autobiographical memory task and completing a questionnaire. The autobiographical memory task would serve as the free will manipulation. Participants were asked to recall a time where they (i) experienced choice and control over the outcome of a situation (profree will condition), (ii) a lack of choice and control over the outcome of a situation (antifree will condition), or (iii) their walk to the psychology building that day (control condition). The autobiographical memory task background and instructions can be found in Appendix C. After completing the autobiographical memory task, participants completed a questionnaire including scales measuring belief in free will, trait selfhandicapping, academic contingency of self-worth, meaning threat, effort beliefs, locus of control, responsibility, general self-efficacy, defensive pessimism, and need for cognitive closure. All scales were presented in a random order, where questions within each scale were randomized. The two attention checks used in Study 1 and Study 2 were also randomly displayed in the survey. Information about new scales used in Study 3 can be found in Appendix D. After the questionnaire was completed, participants opened the door to signal the experimenter, who moved them on to the second task.

In the second task, experimenters told participants that they would be taking two IQ tests: the Kansas Analogies Intelligence Test (KAIT) and the Culture Fair Intelligence Test (CFIT). The IQ tests can be found in Appendix E. The experimental software, MediaLab, informed participants that the CFIT was a new kind of IQ test that controlled 
for the cultural bias in most IQ tests, such as the KAIT. Participants then read that our lab was replicating previous research that had shown a strong positive correlation between the KAIT and the CFIT. This information was given to participants so that they believed that their score on the first IQ test would predict their performance on the second IQ test. In other words, they were led to believe that performing well on the first IQ test meant that they should also perform well on the second IQ test. This information provided participants with a reason for why they were taking two IQ tests, and more importantly communicated an expectation that their performance on the second IQ test should be similar to their performance on the first. This implied that if one performed well on the first IQ test, then, if they are truly intelligent, they should also perform that well on the second IQ test. Poorer performance on the second IQ test would indicate a lack of competence and threaten self-worth.

After receiving this information, participants completed the KAIT (see Appendix E), which is an extremely difficult test in which participants were asked to complete analogies using rare and sesquipedalian words (e.g., sesquipedalian). The KAIT is, however, multiple choice - which afforded participants the opportunity to explain success feedback by believing that they had guessed correctly on questions throughout the test. As such, we expected participants to believe that they had done well on the KAIT when given success feedback, but uncertain about how they had achieved such a high score and concerned about how they would replicate this performance on the second test. After completing the KAIT, participants were given such non-contingent success feedback. Regardless of their actual performance, participants read that they had done very well on the KAIT, and, given this exceptional performance, we expected them to perform equally 
well on the CFIT. Because the KAIT was so difficult and participants likely felt that they had performed poorly, this feedback was meant to arouse uncertainty about the means to successful performance and how to defend a successful self-image by performing well on future assessments. This procedure has been used to arouse self-handicapping in past studies (Jones \& Berglas, 1978; Arkin \& Baumgartner, 1985; Mayerson \& Rhodewalt, 1988; Hirt, Deppe, \& Gordon, 1991).

After the non-contingent success feedback and prior to completing the CFIT, MediaLab presented participants the stress instruction manipulation. The stress instructions either told participants that (i) past research had shown that stress does negatively impact performance on the CFIT or (ii) that stress does not influence performance on the CFIT. In either case, we told participants that we were interested in replicating this past research, and that is why we were having them report their stress levels. For those who were told that stress does negatively influence performance on the CFIT, claiming stress would serve as a viable handicap. For participants who were told that stress does not impact performance on the CFIT, they would not have a viable handicap. The purpose of manipulating handicap viability (i.e., that stress does or does not matter) was to demonstrate that participants are claiming stress as a handicap, rather than merely reporting stress levels. Similar procedures have been used in the past to manipulate handicap viability for the same purpose (Hirt, Deppe, \& Gordon, 1991; Hirt, McCrea, \& Kimble, 2000; Kimble \& Hirt, 2005; McCrea, Hirt, \& Milner, 2008).

After the stress manipulation, participants completed the evaluative concern scale (Hirt, McCrea, and Kimble, 2000), which includes a three subscales, one of which measuring concern for failure. This concern for failure subscale served as our measure of 
uncertainty about future performance and fear of failure. After completing the evaluative concern scale, participants reported their stress, which served as our dependent variable of claimed self-handicapping. If participants were told that stress does negatively impact performance on the CFIT, then by reporting stress participants would be able to blame poor performance on their stress levels, rather than lack of ability. Once they had reported their stress, participants completed the CFIT. Participants then completed suspicion probes and demographic questions, were debriefed, thanked for their participation, and assigned course credit.

\section{Study 3 Results}

\section{Descriptive Statistics}

Participants were 125 students from a large public university in Indiana; however, after filtering out participants who had failed either an attention check or a memory check for the content of the second manipulation, data were analyzed for 98 participants. Mean age was 19.07 years, and 62 participants identified as women and 35 as men, while one participant identified as non-binary. Of the 98 participants whose data were used, 73.5\% identified as White Caucasian, $4.1 \%$ as Black, $16.3 \%$ as Asian, $5.1 \%$ as multiracial, and $1 \%$ as other.

\section{Free Will Manipulation Checks}

A one-way ANOVA revealed no significant difference in free will belief as measured by the FAD-Plus between any of the free will manipulation conditions $(F(2$, $95)=0.69, p=0.504)$. In other words, the free will manipulation failed to change belief in free will.

Additional one-way ANOVAs were conducted to test the effect of the free will 
manipulation on other constructs of interest. These ANOVAs yielded no significant effect of the free will manipulation conditions on internal locus of control $(F(2,95)=0.025, p=$ $0.975)$, concern with failure $(F(2,95)=0.054, p=0.948), \operatorname{GSE}(F(2,95)=2.723, p=$ $0.071)$, chance locus of control $(F(2,95)=2.185, p=0.118)$, responsibility $(F(2,95)=$ $0.231, p=0.794)$, or meaning threat $(F(2,95)=0.125, p=0.882)$.

However, a one-way ANOVA did reveal an unpredicted marginally significant difference in the powerful others subscale of the MLOC between the free will conditions $(F(2,95)=3.305, p=0.041)$. A post-hoc Tukey test (Fig. 1$)$ revealed that belief in powerful others as causal forces in one's life was marginally greater for participants in the anti-free will condition (Mean $=3.75, \mathrm{SD}=.919, p=0.054$ ) as opposed to those in the control condition (Mean $=3.19, \mathrm{SD}=0.86)$. There was no significant difference in belief in powerful others between the anti-free will and pro-free will conditions (Mean = $3.25, \mathrm{SD}=1.02, p=0.85)$ or between the control and pro-free will conditions $(\mathrm{p}=$ 0.966).

\section{Primary Analyses}

We conducted a three-way between subjects factorial ANOVA to examine the effects of the free will manipulation, stress instruction conditions, and trait selfhandicapping on claims of stress. A median split was conducted on scores on the selfhandicapping scale to designate high self-handicappers and low self-handicappers.

Specifically, participants above the median score on the self-handicapping scale were designated as high self-handicappers while those below were designated as low selfhandicappers. The analysis revealed a significant main effect of the trait selfhandicapping $\left(F(1,98)=8.754, p=0.004, \eta^{2}=.092\right)$, such that high self-handicappers 


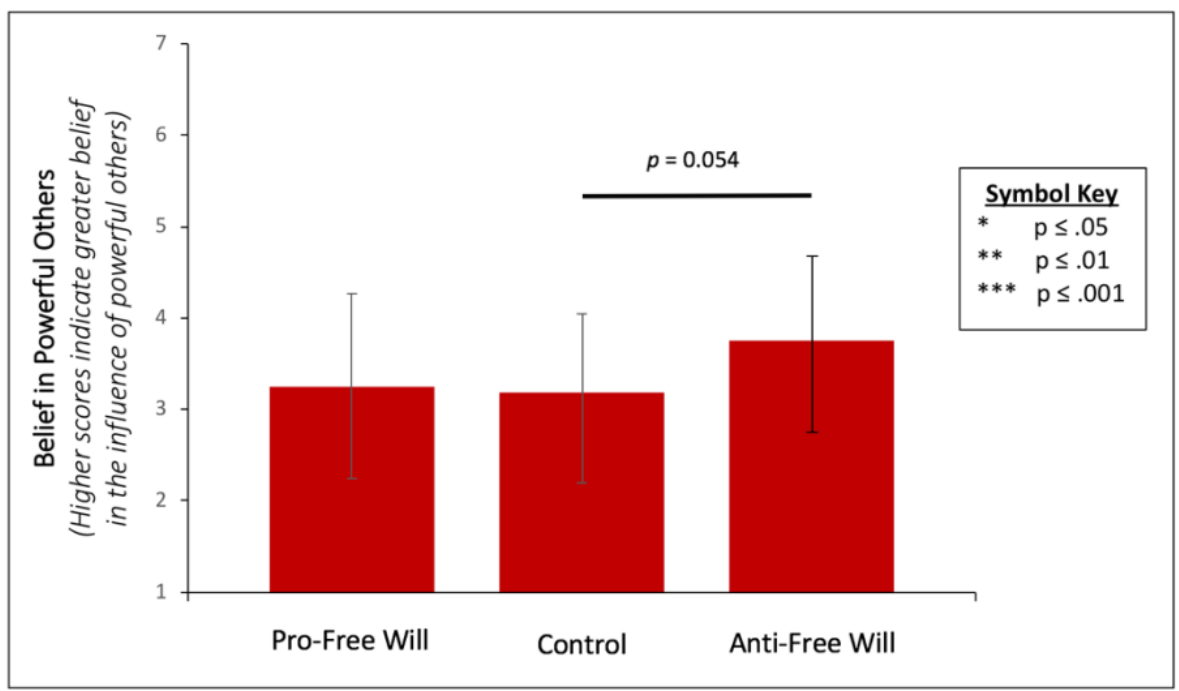

Figure 1. A one-way ANOVA revealed a marginally significant difference in the powerful others subscale of the MLOC between the free will conditions $(F(2,95)=$ $3.305, p=0.041)$. A post-hoc Tukey test showed that belief in powerful others was marginally greater for participants in the anti-free will condition (Mean $=3.75, \mathrm{SD}=$ $.919, p=0.054)$ as opposed to those in the control condition $($ Mean $=3.19, \mathrm{SD}=0.86)$. There was no significant difference in belief in powerful others between the anti-free will and pro-free will conditions (Mean $=3.25, \mathrm{SD}=1.02, p=0.85)$ or between the control and pro-free will conditions ( $\mathrm{p}=0.966$ ). 
$($ Mean $=36.52, \mathrm{SD}=18.92)$ claimed stress as a handicap significantly more than low self-handicappers $($ Mean $=25.36, \mathrm{SD}=16.30)$. (Fig. 2) No other significant main effects or interactions emerged.

\section{Correlations}

Free Will Belief, Self-Handicapping, Concern for Failure, and Effort Value. Free will belief, as measured only by the FAD-Plus in Study 3, was significantly negatively correlated with the SHS $(r=-.199, p=0.05)$ and claimed stress $(r=-.313, p<0.01)$, such that stronger belief in free will was associated with lower trait self-handicapping and less claimed self-handicapping behavior respectively.

Belief in free will was also significantly negatively correlated with the concern for failure subscale of the evaluative concern scale $(\mathrm{r}=-.515, \mathrm{p}<.01)$, such that stronger belief in free will was associated with less concern for failure. Lastly, free will belief was significantly positively correlated with the Worker scale $(\mathrm{r}=.222, \mathrm{p}<.05)$, such that stronger belief in free will was associated with higher value placed on effort.

With regard to the relationship between free will belief and locus of control as measured by the MLOC, free will belief was significantly positively correlated with internal locus of control $(\mathrm{r}=.555, \mathrm{p}<.001)$ and significantly negatively correlated with belief in powerful others $(\mathrm{r}=-.295, \mathrm{p}<.05)$. There was no correlation between belief in free will and the chance subscale of the MLOC.

Self-Handicapping and other Correlates. The SHS was negatively correlated with the Worker scale $(\mathrm{r}=-.362, \mathrm{p}=<.001)$, such that higher trait self-handicapping was associated with lower value placed on effort. Trait self-handicapping was also significantly negatively correlated with internal locus of control $(r=-.289, \mathrm{p}<.01)$, and 


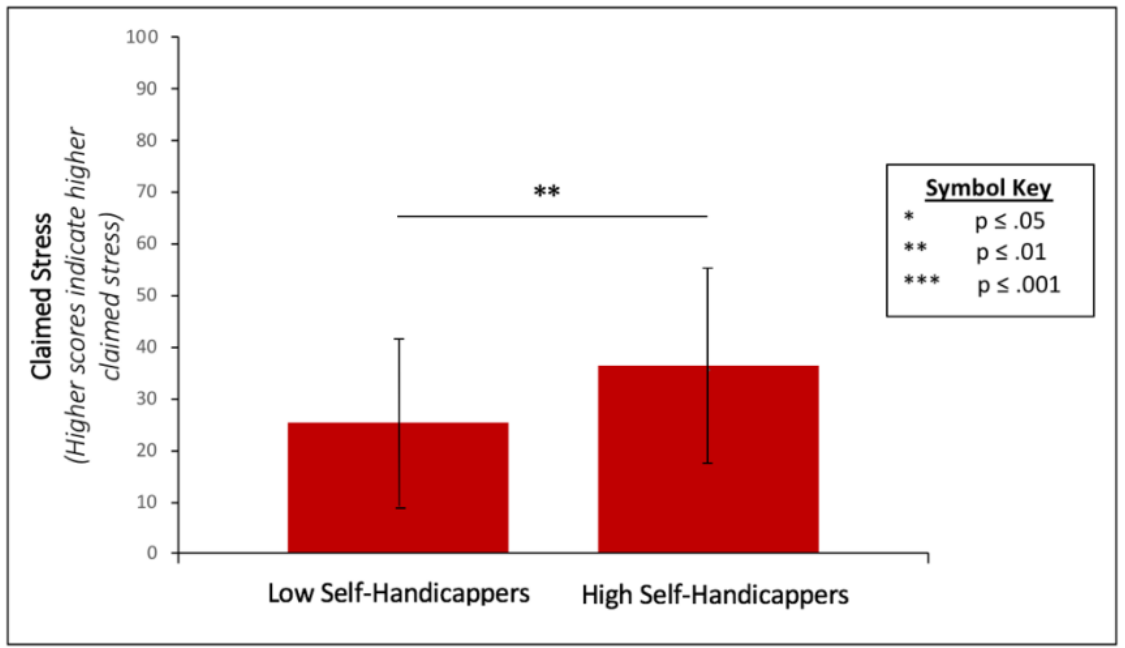

Figure 2. A three-way ANOVA revealed a significant main effect of trait selfhandicapping on claimed stress, such that high self-handicappers claimed stress significantly more than low self-handicappers. $F(1,98)=8.754, p=0.004, \eta^{2}=.092$. 
positively with both external loci of control: chance $(r=.344, p=.001)$ and powerful others $(\mathrm{r}=.429, \mathrm{p}<.001)$. In other words, higher trait self-handicapping was associated with a more external locus of control. Finally, the SHS was significantly positively correlated with our measure of self-handicapping, claimed stress $(r=.400, p<.001)$, such that higher trait self-handicapping was associated with higher claimed self-handicapping.

Unlike trait self-handicapping, claimed stress was not significantly correlated with the Worker scale or the chance subscale of the MLOC. Also, claimed stress was marginally positively correlated with the concern for failure subscale of the evaluative concern scale $(r=.346, p=0.86)$. Like the SHS, claimed stress was significantly negatively correlated with internal locus of control $(r=-.242, p<.05)$ and positively with the powerful others subscale of the MLOC ( $\mathrm{r}=.321, \mathrm{p}<.001)$. Correlations for Study 3 can be found in Table 3 .

\section{Study 3 Discussion}

Study 3 set out to build on the robust correlational data gathered in Study 1 and Study 2. Specifically, Study 1 and Study 2 hypothesized based on past research and theory that belief in free will would be negatively related to trait self-handicapping, such that stronger belief in free will would be associated with lower trait self-handicapping. Both studies found support for this hypothesis. Study 3 used an experimental design attempting to manipulate belief in free will and the viability of a handicap (i.e., selfreported stress) to establish a causal relationship between belief in free will and selfhandicapping, such that decreased belief in free will would increase self-handicapping behavior when a handicap was viable (i.e., when stress mattered for future performance). Moreover, we hypothesized that uncertainty about future performance (i.e., the concern 


\begin{tabular}{|c|c|c|c|c|c|c|c|c|c|}
\hline$N=98^{*}$ & $\begin{array}{l}\text { Self- } \\
\text { Handicapping } \\
\text { Scale }\end{array}$ & $\begin{array}{l}\text { Free Will } \\
\text { Subscale of } \\
\text { FAD-Plus }\end{array}$ & Claimed Stress & $\begin{array}{l}\text { Concern for } \\
\text { Failure }\end{array}$ & Worker Scale & $\begin{array}{l}\text { Internal Locus } \\
\text { of Control }\end{array}$ & $\begin{array}{l}\text { Chance Locus } \\
\text { of Control }\end{array}$ & $\begin{array}{l}\text { Powerful } \\
\text { Others Locus } \\
\text { of Control }\end{array}$ & $\begin{array}{l}\text { Belief in } \\
\text { Personal } \\
\text { Responsibility }\end{array}$ \\
\hline $\begin{array}{r}\text { Self- } \\
\text { Handicapping } \\
\text { Scale }\end{array}$ & 1 & & & & & & & & \\
\hline $\begin{array}{r}\text { Free Will } \\
\text { Subscale of FAD- } \\
\text { Plus }\end{array}$ & $\begin{array}{l}-.199 \\
p=.05\end{array}$ & 1 & & & & & & & \\
\hline Claimed Stress & $\begin{array}{l}.400 \\
p<.001\end{array}$ & $\begin{array}{l}-.313 \\
p<.01\end{array}$ & 1 & & & & & & \\
\hline $\begin{array}{r}\text { Concern for } \\
\text { Failure }\end{array}$ & $\begin{array}{l}-.086 \\
p=.676\end{array}$ & $\begin{array}{l}-.551 \\
p<.01\end{array}$ & $\begin{array}{l}.346 \\
p=.083\end{array}$ & 1 & & & & & \\
\hline Worker Scale & $\begin{array}{l}-.362 \\
p<.001\end{array}$ & $\begin{array}{l}.222 \\
p<.05\end{array}$ & $\begin{array}{l}-.078 \\
p=.445\end{array}$ & $\begin{array}{l}-.022 \\
p=.915\end{array}$ & 1 & & & & \\
\hline $\begin{array}{r}\text { Internal Locus of } \\
\text { Control }\end{array}$ & $\begin{array}{l}-.289 \\
p<.01\end{array}$ & $\begin{array}{l}.555 \\
p<.001\end{array}$ & $\begin{array}{l}-.242 \\
p<.05\end{array}$ & $\begin{array}{l}-.543 \\
p<.01\end{array}$ & $\begin{array}{l}.187 \\
p=.065\end{array}$ & 1 & & & \\
\hline $\begin{array}{r}\text { Chance Locus of } \\
\text { Control }\end{array}$ & $\begin{array}{l}.344 \\
p=.001\end{array}$ & $\begin{array}{l}-.095 \\
p=352\end{array}$ & $\begin{array}{l}.124 \\
p=.225\end{array}$ & $\begin{array}{l}.073 \\
p=.723\end{array}$ & $\begin{array}{l}-.223 \\
p<.05\end{array}$ & $\begin{array}{l}-.063 \\
p=.539\end{array}$ & 1 & & \\
\hline $\begin{array}{l}\text { Powerful Others } \\
\text { Locus of Control }\end{array}$ & $\begin{array}{l}.429 \\
p<.001\end{array}$ & $\begin{array}{l}-.295 \\
p<.01\end{array}$ & $\begin{array}{l}.321 \\
p=.001\end{array}$ & $\begin{array}{l}.133 \\
p=.516\end{array}$ & $\begin{array}{l}-.248 \\
p<.05\end{array}$ & $\begin{array}{l}-.167 \\
p=.101\end{array}$ & $\begin{array}{l}.538 \\
p<.001\end{array}$ & 1 & \\
\hline $\begin{array}{r}\text { Belief in } \\
\text { Personal } \\
\text { Responsibility }\end{array}$ & $\begin{array}{l}-.303 \\
p<.01\end{array}$ & $\begin{array}{l}.612 \\
p<.001\end{array}$ & $\begin{array}{l}-.249 \\
p<.05\end{array}$ & $\begin{array}{l}-.138 \\
p=.501\end{array}$ & $\begin{array}{l}.321 \\
p=.001\end{array}$ & $\begin{array}{l}.352 \\
p<.001\end{array}$ & $\begin{array}{l}-.199 \\
p<.05\end{array}$ & $\begin{array}{l}-.235 \\
p<.05\end{array}$ & 1 \\
\hline
\end{tabular}

Table 3. Study 3 correlations. 
for failure subscale of the evaluative concern scale) would mediate the relationship between free will and claimed self-handicapping, such that reduced belief in free will would increase uncertainty about future performance, which would increase selfhandicapping behavior.

Unfortunately, our free will manipulation was not successful. That is, there was no difference in free will belief by free will condition. Additionally, while the stress manipulation did successfully shift belief in the impact of stress on test performance, it did not produce differences in claimed stress by the stress condition. While this does not falsify our hypotheses about the causal relationship between belief in free will, uncertainty, and self-handicapping, it does prevent us from conducting an experimental test of our hypotheses. In other words, because we were unable to experimentally manipulate belief in free will, we are unable to examine the causal impact of it on our dependent variable of self-handicapping behavior: claimed stress.

However, correlational data obtained in Study 3 largely replicate the patterns found in Study 1 and Study 2. Namely, belief in free will was negatively correlated with trait self-handicapping and claimed stress. Moreover, in Study 3, we obtained a negative correlation between belief in free will and concern for failure (i.e., uncertainty) as well as a marginal positive correlation between concern for failure and claimed stress. This pattern of correlations is consistent with the mediational hypothesis that weakened belief in free will increases concern for failure, which increases self-handicapping behavior. This suggests that if we could successfully manipulate belief in free will, we would find the hypothesized causal relationship. However, having only correlational data, we are restricted from making such causal claims about the relationship between belief in free 
will, concern for failure, and self-handicapping.

\section{General Discussion}

\section{Hypotheses}

The results from these three studies support much past research in the selfhandicapping literature as well as our own predictions. As past work has shown, selfhandicapping is implemented when participants feel uncertain about the means to success, and thus concerned about the likelihood of failure on a future assessment (Arkin \& Baumgartner, 1985; Mayerson \& Rhodewalt, 1988; Hirt, Deppe, \& Gordon, 1991; Hirt, McCrea, \& Kimble, 2000). This literature motivated the hypothesis in all studies that people who have a weaker belief in free will, or the idea that we are in control of our behavior and that our choices have an impact on the outcomes in our lives (Monroe \& Malle, 2010; Stillman et al., 2011), would be more likely to self-handicap. In Study 3, we further hypothesized that this relationship between belief in free will and selfhandicapping is mediated by concern for future failure. In other words, we hypothesized that holding a weaker belief in free will would lead one to be more uncertain and concerned about their ability to succeed on an upcoming assessment, and this uncertainty would increase self-handicapping.

\section{Correlational Evidence and Implications}

Across all three studies, we found robust correlational support for the hypothesized relationship between belief in free will and self-handicapping. In all three studies, belief in free will was negatively correlated with trait self-handicapping, such that weaker belief in free will was associated with higher trait self-handicapping. In Study 3 , free will belief was also negatively correlated with claimed stress. In addition to being 
replicated successfully, this relationship was found in both an adult MTurk sample and two student samples. In Study 3, we also found a marginal positive correlation between concern for failure and claimed self-handicapping behavior, which is consistent with past work showing that uncertainty about future performance leads to self-handicapping (Arkin \& Baumgartner, 1985; Mayerson \& Rhodewalt, 1988; Hirt, Deppe, \& Gordon, 1991; Hirt, McCrea \& Kimble, 2000). Moreover, consistent with hypotheses, we found in Study 3 that belief in free will was negatively correlated with evaluative concern. In other words, having a weaker belief in free will was associated with greater concern for failure, and having greater concern for failure was associated with higher claimed selfhandicapping behavior. While correlational data does not allow us to make causal claims, this pattern of associations does provide indirect support for the causal hypotheses that (i) weaker belief in free will leads to more self-handicapping and (ii) this relationship is mediated by concern for failure, such that weaker belief in free will induces higher concern for failure, motivating more self-handicapping.

\section{Experimental Manipulations}

Indeed, Study 3 set out to test these causal hypotheses. However, we did not observe differences in self-reported stress between the two stress conditions, and our autobiographical memory task failed to manipulate belief in free will. The failure of the stress instructions to produce differences in self-reported stress is puzzling, as this manipulation has worked several times in our own lab in the past. However, in the past, the stress instructions have typically been delivered verbally by a research assistant, and in Study 3 participants read the stress instructions alone in their private testing cubicle. This could have diminished the efficacy of the stress instructions for several reasons. For 
example, the stress instructions may have been less believable or convincing when being read in a room alone as opposed to read aloud by a research assistant who is, ostensibly, someone knowledgeable about the topic. It is also possible that participants may have felt less motivated to pay attention to the stress instructions while reading them alone as opposed to verbally by a research assistant who is in a position of authority. As a result of these possibilities and the success of the stress instructions in the past, a future replication should have the stress instructions delivered verbally by a research assistant. However, despite the fact that the stress instructions did not produce differences in self-reported stress, the strong positive correlation between trait self-handicapping and self-reported stress suggests that self-reported stress was a valid measure of claimed self-handicapping behavior.

The failure of the free will manipulation to change belief in free will could also be explained in a variety of ways. Most simply, it could be the case that participants are not following the directions. On the one hand, participants in the anti-free will condition who were asked to write about a time when they experienced a lack of choice and control may have completed their written memory by explaining how they ultimately overcame the external forces constraining their freedom, thus bolstering belief in free will rather than weakening it. On the other hand, participants in the pro-free will condition who were asked to write about a time when they had experienced choice and control may have qualified their memory by giving credence to the external forces that did influence their behavior, thus contradicting the positive free will manipulation. If this is the correct explanation for the failure of the manipulation, it could be addressed by giving participants an example of a correctly written memory, by emphasizing that the memory 
should entail complete (lack of) choice and control, or by having a research assistant verbally administer the instructions so that they can emphasize important aspects of them.

It could also be the case that participants are following the directions, but not writing about memories that are impactful enough to change their belief in free will. While some participants may write about emotionally charged life events or transformative experiences that are central to their identities, others may simply write about quotidian activities, such as their decision about what product to buy at the store. Such flat memories may not be evocative enough to change belief in free will. If this is the case, this may be addressed by adding additional information to the memory task instructions that ask the participant to recall a particularly powerful memory.

If either of these two possibilities are true, a content analysis of the written memories may allow us to detect such features of the written memories. In the future, a team of research assistants may code the written memories to see if participants are (i) following directions or (ii) writing about evocative memories. Such information would be invaluable for identifying changes that need to be made to the current manipulation.

It could also be the case that participants are having a hard time recalling instances in which they experienced (lack of) choice and control, and are adjusting their belief in free will accordingly. In other words, if participants are having difficulty writing about a time in which they experienced a lack of choice and control (anti-free will prompt), then they may conclude that such instances do not occur with much frequency, and that this means that they do possess control. Similarly, if participants have a difficult time writing about a situation in which they experienced a lot of choice and control (profree will prompt), they may conclude that such cases are not common in their lives, and 
that external forces often do exert control on them. In either case, the manipulation would essentially be moving attitudes in the opposite direction intended by the manipulation, thus cancelling out cases in which participants do not feel any difficulty writing a memory that fits the prompt.

Indeed, previous research conducted on the availability heuristic has shown that ease of recall for a specific type of memory informs attitudes that correspond with the content of the memories (Schwarz, Bless, Strack, Klumpp, Rittenauer-Schatka, \& Simons, 1991). Specifically, participants who were asked to recall twelve instances in which they were assertive perceived themselves as less assertive than participants who were asked to only recall six instances in which they were assertive. In the context of Study 3 , this information could be used to enhance the free will manipulation to take advantage of the availability heuristic. Rather than being assigned to respond to either a pro-free will memory prompt or an anti-free will memory prompt, participants could simply be asked to recall a higher or lower number of memories depending on the condition they are assigned to. For instance, to reduce belief in free will, participants could be asked to write about twelve instances in which they experienced choice and control, and to strengthen belief in free will they could be asked to write about six.

To move away from memory-based manipulations all-together, participants could read stories about other individuals who have displayed free will or who have succumbed to the power of external forces. In research on free will belief and blame, Gill and Cerce (2017) used historicist narratives to manipulate the perceived free will of a target character. Historicist narratives are, essentially, detailed accounts of a character's life that shaped who they became. Historicist narratives describe the external powers in a 
character's life that exert some force on the character, and the character either gives in to these forces or acts out against them. Adapting historicist narratives to our research, participants may read about a likeable character who either (i) gives in to external pressures in spite of their own desires (anti-free will) or (ii) reacts against external pressures to assert their agency (pro-free will). The use of historicist narratives could negate the necessity of complicated task instructions, be more engaging for participants, and side-step the availability heuristic.

In any case, the failure of the current free will manipulation to change belief in free will prevents us from conducting an actual experimental test of our hypotheses. It may indeed be the case the weakened belief in free will increases claimed selfhandicapping behavior, and that this relationship is mediated by concern for failure. The failure of the free will manipulation does not constitute evidence against either of these hypotheses. On the contrary, the pattern of correlations found in all three studies provides robust support for the proposed relationship between belief in free will and selfhandicapping, while the correlations found in Study 3 provide support for the mediating role of concern for failure. These correlations suggest that if belief in free will could be successfully manipulated, we would find experimental support for these causal hypotheses. As such, future research should examine alternative free will manipulations, such as improved memory task instructions or historicist narratives, to be able to conduct an experimental test of the hypotheses. That free will belief has been successfully manipulated multiple times in previous literature (Vohs \& Schooler 2008; Alquist, Ainsworth, \& Baumeister, 2013; Gill \& Cerce, 2017; Monroe, Brady, \& Malle, 2017) is clear evidence that such a manipulation is possible, and that a proper test of our causal 
hypotheses is as well.

\section{Conclusion}

Previous research shows that non-contingent success feedback and concern for failure promote the use of self-handicapping as a self-protective strategy. This suggests that self-handicappers feel a lack of control with respect to the outcome of their performance and that their choices have little impact on their performance. Belief in free will is essentially the belief in personal control and choice capacity - that exerting our agency and making choices determine the outcomes in our lives. Thus, it follows that reduced belief in free will would increase the use of self-handicapping, and that this relationship would be explained by the influence of belief in free will on concern for failure. In other words, having a weaker belief in free will increases concern for failure, and increased concern for failure motivates self-handicapping. Studies 1 and 2 found correlational support for the relationship between belief in free will and trait selfhandicapping, such that weaker belief in free will is associated with higher trait selfhandicapping. In Study 3, an experiment attempted to manipulate belief in free will and the viability of a handicap to test these hypotheses causally. Both the free will manipulation and the stress manipulation (i.e., handicap viability) failed to change belief in free will or self-reported stress, respectively. As such, Study 3 was unable to test the causal hypotheses. However, Study 3 replicated the correlations found in Study 1 and Study 2 and found suggestive evidence for the mediating role of concern for failure. As such, it remains an open question whether or not belief in free will has a causal impact on self-handicapping behavior, and whether this relationship is explained by concern for failure. However, correlational data suggest that free will belief does influence self- 
handicapping behavior, and that this is mediated by concern for failure. To answer these questions, future research should seek to manipulate belief in free will to conduct a test of these hypotheses and provide direct experimental support. Such research would explicate the causal antecedents to self-handicapping, and tell us why, in the face of uncertainty and potential failure, some choose to self-handicap while others choose to put forth more effort towards success. This information would inform applied work to prevent the use of self-handicapping, and the harmful consequences that come with it. 


\section{References}

Alquist, J. L., Ainsworth, S. E., \& Baumeister, R. F. (2013). Determined to conform: Disbelief in free will increases conformity. Journal of Experimental Social Psychology, 49(1), 80-86.

Arkin, R. M., \& Baumgardner, A. H. (1985). Self-handicapping. In J. H. Harvey \& G. Weary (Eds.), Attribution: Basic issues and applications (pp. 169-202). New York, NY: Academic Press.

Baumeister, R. F., \& Brewer, L. E. (2012). Believing versus disbelieving in free will: Correlates and consequences. Social and Personality Psychology Compass, 6(10), 736-745.

Berglas, S., \& Jones, E. E. (1978). Control of attributions about the self through selfhandicapping strategies: The appeal of alcohol and the role of underachievement. Personality and Social Psychology Bulletin, 4(2), 200-206.

Berglas, S., \& Jones, E. E. (1978). Drug choice as a self-handicapping strategy in response to noncontingent success. Journal of Personality and Social Psychology, $36(4), 405$.

Crescioni, A. W., Baumeister, R. F., Ainsworth, S. E., Ent, M., \& Lambert, N. M. (2015). Subjective correlates and consequences of belief in free will. Philosophical Psychology, 1-23.

Crocker, J., Luhtanen, R. K., Cooper, M. L., \& Bouvrette, A. (2003). Contingencies of self-worth in college students: theory and measurement. Journal of personality and social psychology, 85(5), 894.

Deery, O., Davis, T., \& Carey, J. (2015). The Free-Will Intuitions Scale and the question 
of natural compatibilism. Philosophical Psychology, 28(6), 776-801.

Gill, M. J., \& Cerce, S. C. (2017). He never willed to have the will he has: Historicist narratives, "civilized" blame, and the need to distinguish two notions of free will. Journal of personality and social psychology, 112(3), 361.

Hirt, E. R., Deppe, R. K., \& Gordon, L. J. (1991). Self-reported versus behavioral Selfhandicapping: Empirical evidence for a theoretical distinction. Journal of Personality and Social Psychology, 61, 981-991.

Hirt, E. R., McCrea, S. M., \& Kimble, C. E. (2000). Public self-focus and sex differences in behavioral self-handicapping: Does increasing self-threat still make it "just a man's game?". Personality and Social Psychology Bulletin, 26(9), 1131-1141.

Jamieson, J. P., Harkins, S. G., \& Williams, K. D. (2010). Need threat can motivate performance after ostracism. Personality and Social Psychology Bulletin, 36(5), 690-702.

Jones, E. E., \& Rhodewalt, F. (1982). The self-handicapping scale. Princeton, NJ: Princeton University.

Kanner, A. D., Coyne, J. C., Schaefer, C., \& Lazarus, R. S. (1981). Comparison of two modes of stress measurement: Daily hassles and uplifts versus major life events. Journal of behavioral medicine, 4(1), 1-39.

Kimble, C. E., \& Hirt, E. R. (2005). Self-focus, gender, and habitual self-handicapping: Do they make a difference in behavioral self-handicapping?. Social Behavior and Personality: an international journal, 33(1), 43-56.

Lefcourt, H. M., von Baeyer, C. L., Ware, E. E., \& Cox, D. J. (1979). The multidimensional-multiattributional causality scale: The development of a goal 
specific locus of control scale. Canadian Journal of Behavioural Science/Revue canadienne des sciences du comportement, 11(4), 286.

Levenson, H. (1973). Multidimensional locus of control in psychiatric patients. Journal of consulting and clinical psychology, 41(3), 397.

Mayerson, N. H., \& Rhodewalt, F. (1988). Role of self-protective attributions in the experience of pain. Journal of Social and Clinical Psychology, 6(2), 203-218.

McCrea, S. M., \& Hirt, E. R. (2001). The role of ability judgments in self- handicapping. Personality and Social Psychology Bulletin, 27(10), 1378-1389.

McCrea, S. M., Hirt, E. R., Hendrix, K. L., Milner, B. J., \& Steele, N. L. (2008). The worker scale: Developing a measure to explain gender differences in behavioral self-handicapping. Journal of Research in Personality, 42(4), 949-970.

McCrea, S. M., Hirt, E. R., \& Milner, B. J. (2008). She works hard for the money: Valuing effort underlies gender differences in behavioral selfhandicapping. Journal of Experimental Social Psychology, 44(2), 292-311.

Monroe, A. E., Brady, G. L., \& Malle, B. F. (2017). This isn’t the free will worth looking for: General free will beliefs do not influence moral judgments, agent-specific choice ascriptions do. Social Psychological and Personality Science, 8(2), 191199.

Monroe, A. E., \& Malle, B. F. (2010). From uncaused will to conscious choice: The need to study, not speculate about people's folk concept of free will. Review of Philosophy and Psychology, 1(2), 211-224.

Norem, J. K., \& Cantor, N. (1986). Anticipatory and post hoc cushioning strategies: Optimism and defensive pessimism in "risky" situations. Cognitive therapy and 
research, 10(3), 347-362.

Paulhus, D. L., \& Carey, J. M. (2011). The FAD-Plus: Measuring lay beliefs regarding free will and related constructs. Journal of personality assessment, 93(1), 96-104.

Rakos, R. F., Laurene, K. R., Skala, S., \& Slane, S. (2008). Belief in free will: Measurement and conceptualization innovations. Behavior and Social Issues, 17(1), 20.

Rhodewalt, F., Morf, C., Hazlett, S., \& Fairfield, M. (1991). Self-handicapping: The role of discounting and augmentation in the preservation of self-esteem. Journal of Personality and Social Psychology, 61(1), 122.

Rosenberg, M. (1965). Rosenberg self-esteem scale (RSE). Acceptance and commitment therapy. Measures package, 61, 52.

Schwarz, N., Bless, H., Strack, F., Klumpp, G., Rittenauer-Schatka, H., \& Simons, A. (1991). Ease of retrieval as information: Another look at the availability heuristic. Journal of Personality and Social psychology, 61(2), 195.

Schwinger, M., Wirthwein, L., Lemmer, G., \& Steinmayr, R. (2014). Academic selfhandicapping and achievement: A meta-analysis. Journal of Educational Psychology.106(3), 744-761.

Stillman, T. F., Baumeister, R. F., \& Mele, A. R. (2011). Free will in everyday life: Autobiographical accounts of free and unfree actions. Philosophical Psychology, 24(3), 381-394.

Stillman, T. F., Baumeister, R. F., Vohs, K. D., Lambert, N. M., Fincham, F. D., \& Brewer, L. E. (2010). Personal philosophy and personnel achievement: Belief in free will predicts better job performance. Social Psychological and Personality 
Science, 1(1), 43-50.

Schwarzer, R., Bäßler, J., Kwiatek, P., Schröder, K., \& Zhang, J. X. (1997). The assessment of optimistic self-beliefs: comparison of the German, Spanish, and Chinese versions of the general self-efficacy scale. Applied Psychology, 46(1), 69-88.

Vohs, K. D., \& Schooler, J. W. (2008). The value of believing in free will: Encouraging a belief in determinism increases cheating. Psychological science, 19(1), 49-54.

Webster, D. M., \& Kruglanski, A. W. (1994). Individual differences in need for cognitive closure. Journal of personality and social psychology, 67(6), 10.

Zuckerman, M., Kieffer, S. C., \& Knee, C. R. (1998). Consequences of self-handicapping: Effects on coping, academic performance, and adjustment. Journal of personality and social psychology, 74(6), 1619.

Zuckerman, M., \& Tsai, F. F. (2005). Costs of self-handicapping. Journal of Personality, 73(2), 411-442. 


\section{Appendix A: Study 1 Measures}

Attention Checks. Two attention check questions were included in the survey. These checks were intended to filter out lower quality responses from participants who may have been distracted, not reading the questions completely, or simply rushing. They read, "While watching television, I've had a fatal heart attack" and "If you're paying attention, please select two for this item".

Free Will Intuitions Scale. The Free-Will Intuitions Scale (FWIS) was designed by experimental philosophers to empirically measure folk intuitions regarding the nature of free will (Deery et al., 2015). It includes measures on moral responsibility, sourcehood and ability-to-do-otherwise notions of both compatibilism and incompatibilism, as well as distal and proximal determinism. Sourcehood and ability-to-do-otherwise notions of free will are the two main philosophical positions for what is necessary and sufficient for us to have free will. The sourcehood view of free will holds that someone is free if and only if they are the source of their actions. The ability-to-do-otherwise view conversely states that we are free if and only if we could have done otherwise, given the exact same conditions. Compatibilism simply states that free will is still possible given determinism, whereas incompatibilism (AKA "hard determinism") holds that free cannot be reconciled with determinism and is merely an illusion. Specifically, in this study, participants were asked to complete the Sourcehood Compatibilism and Ability-To-Do-Otherwise Compatibilism subscales for the sake of relevance and survey length. These subscales measure the degree to which participants agree with a sourcehood compatibilist notion of free will and an ability-to-do-otherwise compatibilist notion of free will, respectively. Subjects read a series of brief vignettes and rated their agreement with them on a 7-point 
Likert scale (1 = "Strongly Disagree"; 7 = "Strongly Agree"). Higher scores indicate a stronger agreement with the concepts described in each subscale, while lower scores indicate the opposite.

FAD-Plus Scale. Participants were instructed to complete the Free Will subscale of the FAD-Plus (Paulhus \& Carey, 2011). Although the FAD-Plus contains subscales for free will, scientific determinism, fatalistic determinism, and unpredictability, only the free will subscale was included for the sake of survey length and relevance to the study's focus. This subscale measures the extent to which participants endorse a general belief in free will operationalized as human control over their actions. To do so, participants responded to a series of questions on a 5-point Likert scale (1 = "Strongly Disagree"; 5 $=$ "Strongly Agree"). Higher scores indicate a stronger belief in free will, whereas lower scores indicate a weaker belief in free will.

Free Will and Determinism Scale. To measure participant's beliefs about their own level of free will (as opposed to humans more generally), participants were asked to complete the Personal Will subscale of the Free Will and Determinism Scale (Rakos et al., 2008). Participants read a series of first-person statements related to free will and indicated the degree to which they found each statement to be true of themselves on a 5point Likert scale ( 1 = "not true at all"; 5 = "almost always true"). Higher scores indicate a strong belief in personal free will, while lower scores indicate a weaker belief in personal free will.

Self-Handicapping Scale. Participants were asked to complete the SelfHandicapping Scale (Jones \& Rhodewalt, 1982). The SHS is comprised of 25-items designed to measure a participant's tendency to engage in self-handicapping and excuse- 
making behavior. Participants read each statement and rated the degree to which they agreed on a 6-point Likert scale ( 0 = “disagree very much"; 5 = "agree very much”). Higher scores indicate a higher inclination to self-handicap, while lower scores indicate a lower inclination.

Worker Scale. In order measure beliefs about effort, participants completed the Worker scale (McCrea et al., 2008). Participants read a series of statements about effort and hard work and rated their level of agreement with each statement on a 6-point Likert scale ( 0 = "disagree very much"; 5 = "agree very much"). Higher scores on the Worker scale indicate a greater value placed on effort and hard work, whereas lower scores indicate a lower amount of value placed on effort and hard work.

Contingencies of Self-Worth Scale. In order to consider contingencies of selfworth, participants completed the academic competence and approval from others subscales of the Contingencies of Self-Worth Scale (Crocker et al., 2003). Each subscale is concerned with the degree to which self-esteem is contingent upon either academic performance or approval from others, respectively. Responses to each item were made on a 7-point Likert scale (1= "Strongly Disagree"; 7 = "Strongly Agree"). Higher scores on a subscale indicate that it is a higher source of self-esteem for the participant, while a lower score indicates that self-esteem is not as dependent on the construct.

General Self-Efficacy Scale. To measure self-efficacy, participants were asked to fill out the General Self-Efficacy Scale (Schwarzer et al., 1997). Participants read firstperson statements about self-efficacy and rated their truthfulness about themselves on a 4-point Likert scale ( $1=$ Not true at all; $4=$ Exactly true). Higher scores indicate a stronger belief in self-efficacy, while lower scores indicate a weaker belief in self- 
efficacy.

Multidimensional Multi-Attributional Causality Scale. For one measure of control, participants were instructed to complete the achievement subscale of the MMCS (Lefcourt et al., 1979). The achievement subscale is designed to understand participants' locus of control for achievement. This 24-item subscale contains 12 questions concerned with success and another 12 with failure. The achievement subscale is further divided into four subscales, two associated with an internal locus of control (ability and effort), and two associated with an external locus of control (context and luck). Each item was rated by participants on a 4-point Likert scale $(0=$ "Strongly Disagree"; $4=$ "Strongly Agree”). Higher scores indicate an external locus of control and scores on individual subscales shed more light on a participant's specific perceived locus of control for achievement.

Multidimensional Locus of Control Scale. To examine general beliefs about locus of control, participants completed the Multidimensional Locus of Control Scale (Levenson, 1973). This scale is broken up into three subscales to measure internality, control by powerful others, and chance. Therefore, the scale indicates whether participants believe that events in life are controlled by themselves, powerful others, or chance forces. Participants responded to a series of items on a 6-point Likert scale $(1=$ "Strongly Disagree"; 6 = "Strongly Agree”). The higher the score on a particular subscale indicates a participant's perceived locus of control for life's events in internal forces, powerful others, or chance. 


\section{Appendix B: Study 2 New Measures}

Free Will Intuitions Scale - Moral Responsibility Subscale. The Free-Will Intuitions Scale (FWIS) was designed by experimental philosophers to empirically measure folk intuitions regarding the nature of free will (Deery et al., 2015). Specifically, in this study, participants were asked to complete the moral responsibility subscale. This subscale measures the degree to which participants believe that people are to be held personally responsible for their behavior. Subjects read a series of brief vignettes and rated their agreement with them on a 7-point Likert scale $(1=$ "Strongly Disagree"; $7=$ "Strongly Agree"). Higher scores indicate a stronger agreement with moral responsibility, while lower scores indicate the opposite.

FAD-Plus Scale. Participants were instructed to complete all subscales of the FAD-Plus (Paulhus \& Carey, 2011). This included subscales for free will, scientific determinism, fatalistic determinism, and randomness. Each subscale measures the extent to which participants endorse a general belief in the construct it is designed to measure. To do so, participants responded to a series of questions on a 7-point Likert scale $(1=$ "Strongly Disagree"; 7 = "Strongly Agree"). Higher scores indicate stronger agreement, whereas lower scores indicate a weaker one.

Free Will and Determinism Scale. To have an additional measure of participant's beliefs about free will, participants were asked to complete all subscales of the Free Will and Determinism Scale (Rakos et al., 2008). Regarding free will specifically, the FWDS included the Personal Will subscale, which measured peoples' beliefs about their own personal free will and the General Will subscale. Three subscales measuring attitudes toward punishment were also added, these scales measured beliefs 
about the validity of retributive, rehabilitative, deterrent punishment respectively. Participants read a series of first-person statements and indicated the degree to which they found each statement to be true on a 7-point Likert scale ( 1 = "not true at all"; $5=$ "almost always true"). Higher scores indicate a strong belief in the construct, while lower scores indicate a weaker belief.

Implicit Person Theory Scale. The implicit person theory scale has been used by researchers to understand someone's mindset towards personality change. The scale is comprised of nine questions asking questions about growth and fixed mindsets. Participants read a series of first-person statements and indicated the degree to which they found each statement to be true on a 7-point Likert scale (1 = "strongly disagree"; 7 $=$ "strongly agree"). Higher scores indicate a more fixed mindset while lower scales more growth.

Rosenberg Self-Esteem Scale. The Rosenberg Self-Esteem scale (Rosenberg, 1965 ) is used to measure someone's global feeling of self-esteem. Participants are given 10 statements, such as "On the whole, I am satisfied with myself.", and asked to agree or disagree on a 7-point Likert scale (1 = "strongly disagree"; 7 = "strongly agree"). Higher scores indicate higher self-esteem while lower scores indicate lower self-esteem. 


\section{Appendix C: Autobiographical Memory Task Information}

\section{Background}

In this study, we aim to extend findings at Cornell University showing that people with a better memory are more emotionally intelligent. Emotional intelligence has been positively associated with a variety of positive life outcomes, including quality of friendships (Penebaker, 2010) and academic performance (Heltzel, 2016). On the following page, you will be asked to recall and describe a specific type of past life event to measure the ease with which you can create detailed recollections of past events. You will then answer a variety of questions about your thoughts, beliefs, and feelings that we think might explain the relationship between memory and emotional intelligence.

\section{Task Instructions}

\section{Anti-Free Will Condition}

In the space below, describe an event in which you experienced a lack of control over yourself, your choices, and the situation. For instance, you may think of a time when you felt like you didn't have a lot of options, that your choices weren't going to make a difference, and that you didn't have control over the outcome of a situation - where you were a victim of your fate. Take approximately 5 minutes to describe each element of your memory as it comes to your mind in as much detail as possible, including the events that unfolded, the emotions you felt, and the thoughts you had.

\section{Pro-Free Will Condition}

In the space below, describe an event in which you exerted control over yourself, your choices, and the situation. For instance, you may think of a time when you felt like you had a lot of options, that your choices were going to make a large difference, and that you had control over the outcome of a situation - where you were the master of your fate. Take approximately 5 minutes to describe each element of your memory as it comes to your mind in as much detail as possible, including the events that unfolded, the emotions you felt, and the thoughts you had.

\section{Control Condition}

In the space below, describe your walk to this building. For instance, you may describe the path you took, the buildings you passed, or the people you saw on your way. Describe each element of your memory as it comes to your mind, including the events that unfolded, the emotions you felt, and the thoughts you had. 


\section{Appendix D: Study 3 Questionnaire}

Assessment of Need Satisfaction: Meaningful Existence Subscale. To test the possibility that the anti-free will condition led to increases self-handicapping via general existential threat, participants were instructed to complete the meaningful existence subscale of the Assessment of Need Satisfaction scale (Jamieson, Harkins, \& Williams, 2010). This subscale measures the degree to which one feels that they are important and have a meaningful existence. To do so, participants responded to a series of questions on a 7-point Likert scale (1 = "Strongly Disagree"; 7 = "Strongly Agree"). Higher scores indicate that someone feels that they have a meaningful existence, whereas lower scores indicate that someone feels as though they do not have a meaningful existence.

Defensive Pessimism Scale. Participants were asked to complete the defensive pessimism scale (Cantor \& Norem, 1986). The defensive pessimism scales measures trait defensive pessimism. Defensive pessimism is a cognitive strategy where an individual sets low expectations for future performance in order to guard themselves from the implications of failure. To do so, participants responded to a series of questions on a 7point Likert scale (1 = "Strongly Disagree"; 7 = "Strongly Agree"). Higher scores on the defensive pessimism scale indicate higher trait defensive pessimism while lower scores indicate lower trait defensive pessimism.

Need for Cognitive Closure. Participants completed the need for cognitive closure (NFC) scale (Webster \& Kruglanski, 1994). Need for cognitive closure is an individual difference measure comprised of various cognitive and epistemic preferences. Specifically, need for cognitive closure is broken into five subscales - desire for predictability, preference for order and structure in one's environment, discomfort with 
ambiguity, decisiveness, and lose-mindedness. To complete the NFC scale, participants responded to a series of questions on a 7-point Likert scale (1 = "Strongly Disagree"; 7 = "Strongly Agree"). Higher scores indicate need for cognitive closure while lower scores indicate lower need for cognitive closure.

Daily Hassles Scale. To give participants an opportunity to handicap, we had participants complete the Daily Hassles Scale (DHS; Kanner, Coyne, Schaeffer, \& Lazarus, 1981), which served as our dependent measure of claimed self-handicapping. The DHS measures the amount and severity of daily hassles that an individual experiences on an everyday basis that contribute to their level of stress. To complete the DHS, participants ranked the severity with which they experience a variety of daily hassles (e.g., concerns about meeting high standards) on a 4-point Likert scale $(0=$ "Not at all"; 3 = "Extremely Severe"). Higher scores indicate more severe experiences of daily hassles and stressors.

Evaluative Concern. To test the hypothesis that reduced belief in free led to increased uncertainty about future performance, participants completed a measure of evaluative concern (Hirt, McCrea, and Kimble, 2000). Within the evaluative concern scale was a subscale for concern for failure. The concern for failure subscale measures the degree to which a person is uncertain about future performance and sets expectations of failure. Participants responded to the questions on a 7-point Likert scale $(1=$ "Not at all"; 7 = "Very Much"). Higher scores indicate greater evaluative concern while lower scores indicate lower evaluative concern. 


\section{Appendix E: IQ Tests}

\section{$\underline{\text { Kansas Analogies Intelligence Test }}$}

Instructions: For the following items, choose the answer that best fits the analogy.

HUNGRY : LION :: BUSY :

1. SQUIRREL

2. HARE

3. BEAVER

4. CHIPMUNK

Choose the answer which best completes the relationship, "Hungry is to lion as busy is to ."

The correct answer is 3 . BEAVER

Both "hungry as a lion" and "busy as a beaver" are common sayings

Please ask the experimenter now if you have any questions.

You may press the space bar when you are ready to begin the analogy exam.

1) PEACE : DOVE :: WAR :
a. Falcon
b. Hawk
c. Blue Jay
d. Vulture

2) ARM : ELBOW :: LEG :
a. Thigh
b. Shin
c. Knee
d. Calf

3) BRUNETTE : DARK BROWN :: HOARY :
a. Red
b. Yellow
c. Black
d. White

4) TELLER : BANK :: CROUPIER :
a. Casino
b. Caucus
c. Circus
d. Concert

5) SOLDIER : PRIEST :: INDUCTION :
a. Confirmation
b. Graduation
c. Ordination
d. Resistance

6) BRONZE : COPPER :: PEWTER :
a. Iron 

b. Steel
c. Tin
d. Brass

7) GRIFFIN : PHOENIX :: MINOTAUR :
a. Lion
b. Unicorn
c. Serpent
d. Eagle

8) BURNOOSE : CASSOCK :: ARAB :
a. Caftan
b. Priest
c. Hummock
d. Shepherd

9) DESIDERATUM : DESIDERATA :: MAN :
a. Women
b. Principle
c. Men
d. Participle
10) SOUP : TUREEN :: WINE :
a. Cask
b. Snifter
c. Flagon
d. Glass

11) PEEP : ROAR :: CLUTCH :
a. Pride
b. Shift
c. Hold
d. Spy

12) IMAGES : ICONOCLAST :: PROPERTY :
a. Architect
b. Vandal
c. Curator
d. Thief

13) MEDITATE : MASTICATE :: BRAIN :
a. Arm
b. Larynx
c. Nerves
d. Teeth

14) BEING : KNOWLEDGE :: ONTOLOGY :
a. Axiology
b. Epistemology
c. Teleology
d. Eschatology 
15) WAGON : NAPOLEON :: WAINWRIGHT :
e. Baker
f. Coin
g. General
h. Statue

CFIT Practice Problems and Instructions

\author{
PATTERN-DETECTION TEST \\ DIRECTIONS: Please read carefully!
}

For the next portion of the experiment, you will be taking a novel test of your academic abilities. This test, developed through extensive psychological research, will present you with a series of questions about pattern-detection. Each question will require you to observe a specific picture and select which of the other pictures can meet the same spatial requirements.

Because you have likely not completed problems like these before, you will be presented with an example problem before starting the test. This example problem should help clarify the task for you.

\title{
EXAMPLE PROBLEM
}

The instructions for the test are as follows: Look at the example given on the left to see how the $\operatorname{dot}(\mathrm{s})$ are arranged within the figure. Then find the answer choice in which you could put a $\operatorname{dot}(\mathrm{s})$ somewhere inside of it to meet the same criteria as the example you are given. For example, a dot may need to be inside/outside of a certain figure, or on/below/above a certain line. Try to figure out the correct answer to this example.
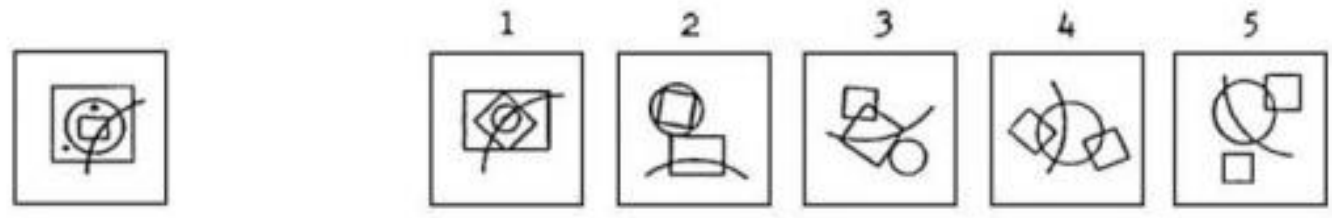

Correct! Notice how in the figure on the left, one dot is in the larger quadrilateral figure but is not in the other two figures, and the other dot is inside both the circle and larger quadrilateral figure but not in the smaller quadrilateral figure. Both dots are above the outside of the curved line.

1)

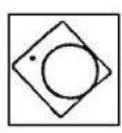

2)

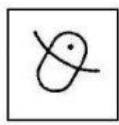

3)

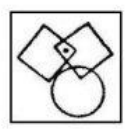

4)

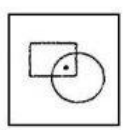

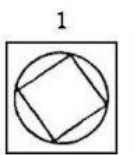
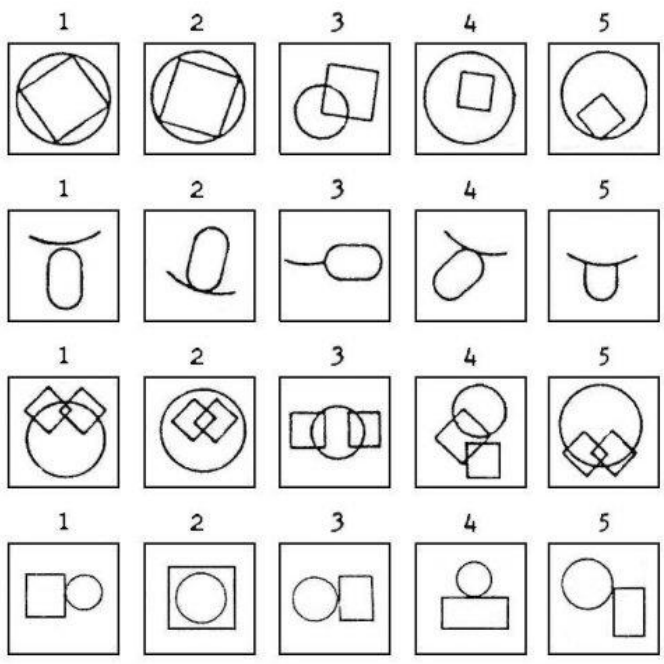

2
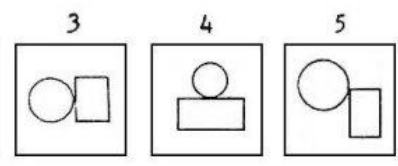


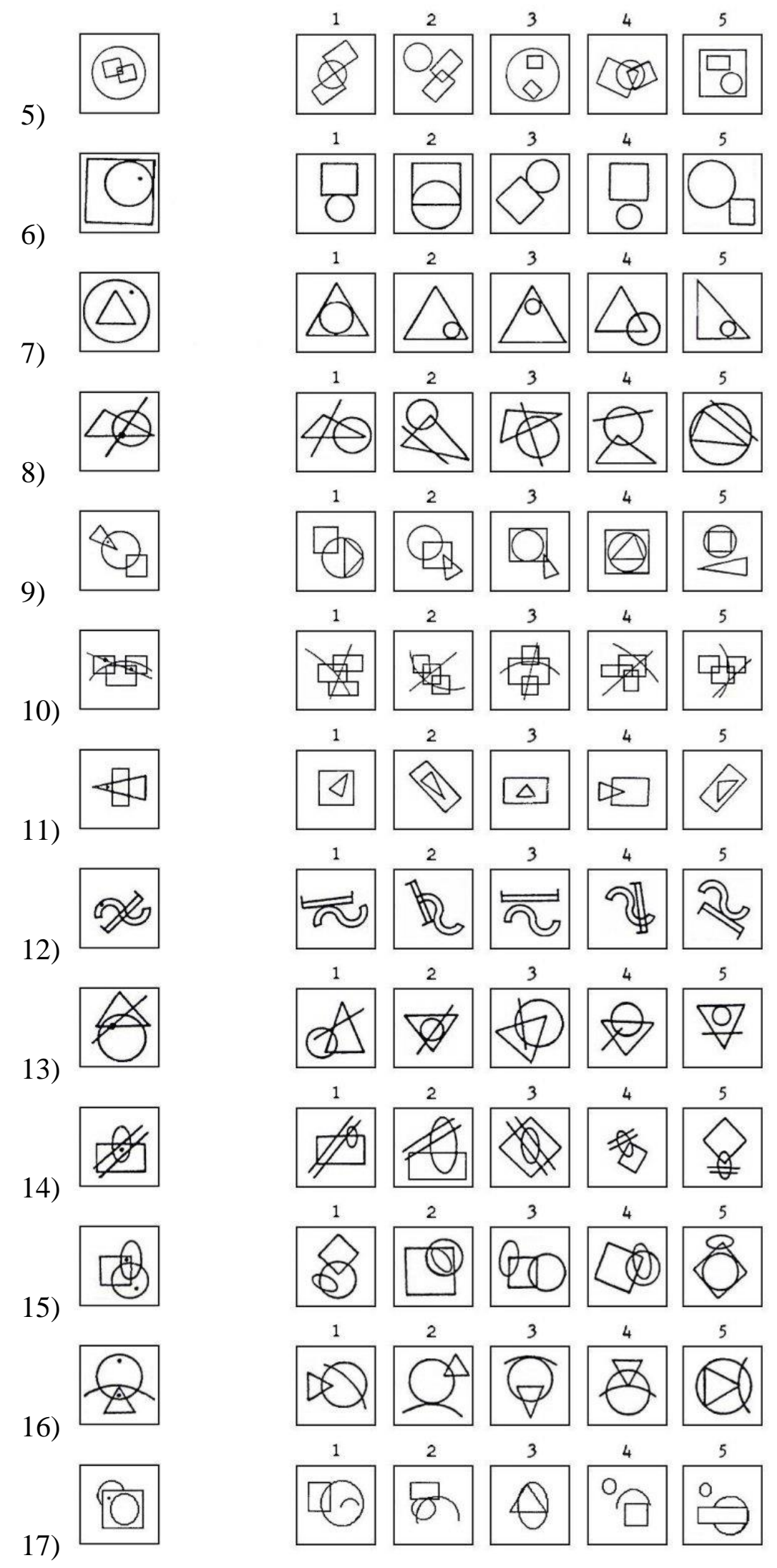




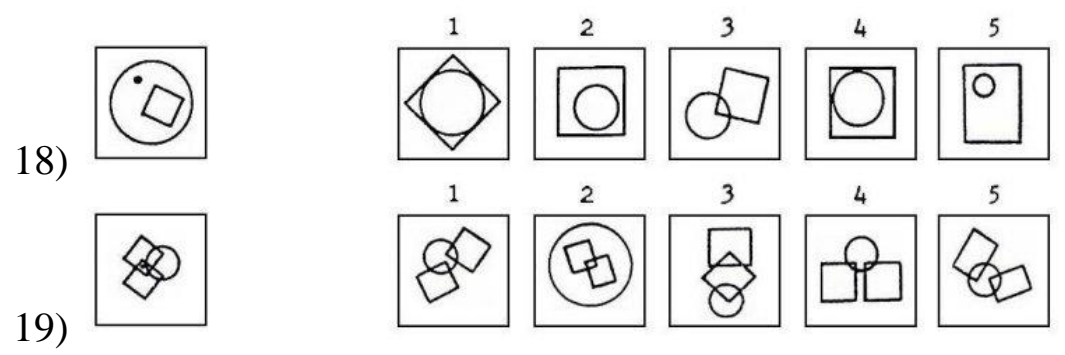

